\title{
Modelos psicolinguísticos de produção da linguagem verbal oral
}

Leonor Scliar-Cabral ${ }^{a}$

\begin{abstract}
Resumo
Os modelos psicolinguísticos de produção da linguagem verbal se deparam com a dificuldade de formalizar as representações mentais das intenções pragmáticas para produzir um texto oral, bem como a dos conceitos essenciais, ambos com a função de orientar o planejamento textual. Tal dificuldade ocasiona desafios a designs experimentais que possam falsear hipóteses de trabalho (POPPER, 2004, p. 41-43). A maior parte dos modelos psicolinguísticos de produção da linguagem verbal oral se refere à abertura de um tópico e não ao diálogo em curso, na sequência à fala de um interlocutor. Aludo aos precursores, provindos da neurologia, como Broca (2004) e Wernicke (CAMPOS FILHO, 2002-2003) e examino os modelos psicolinguísticos, começando pelo pioneiro de Fromkin (1973), detendo-me, em maior profundidade no de Levelt e colegas (1999), com os aportes mais recentes (ROELOFS; FERREIRA, 2017). Os exemplos são todos adaptados ao português brasileiro $(P B)$. Concluo com a hipótese de que, à medida que os níveis de processamento se tornam mais baixos, com paradigmas fechados, constituídos por um menor número de elementos, os processamentos são automatizados e encapsulados. Tal enfoque vai ao encontro da proposta de Fodor (1983), ao dividir os processamentos mentais em horizontais (os chamados processamentos criativos) e verticais (os processamentos compulsórios e modulares).
\end{abstract}

Palavras-Chave: Modelos psicolinguísticos. Produção verbal oral. Intenção pragmática. Mensagem. Planejamento.

Recebido em: 08/01/2018 Aceito em: 22/07/2018

\footnotetext{
a Pós-Graduação em Linguística. Departamento de Língua e Literatura Vernáculas. Universidade Federal de Santa Catarina. E-mail: leonorsc20@gmail.com.
} 
${ }^{1}$ Intenções pragmáticas: são o que o produtor deseja obter do receptor com o texto: pode ser uma mudança de comportamento, através da persuasão, ou pode ser uma resposta linguística, como, por exemplo, uma confirmação ou uma negação, ou uma informação.

${ }^{2}$ BREHM; GOLDRICK, 2016, p. 504: This is because planning a sentence is inherently resource demanding; within a brief time span, speakers must resolve competition between co-activated representations in order to correctly situate multiple items of the same lexical category within a hierarchicallyordered frame.

${ }^{3}$ Léxico mental: constituído por unidades dotadas de significado que são arquivadas na memória permanente, à medida que o indivíduo as percebe e recorta, usadas nos mesmos contexto de uso. Há diferentes léxicos, arquivados em áreas distintas do cérebro, mas a divisão maior é entre os vários léxicos ligados às referências externas à gramática de qualquer língua, abertos ao registro contínuo de novas entradas e o léxico gramatical, ligado às estruturas sintáticas, em número fechado e limitado.

\section{Introdução}

Não tem sido fácil aos cientistas elaborar modelos de produção da linguagem verbal: eles se deparam com várias dificuldades metodológicas, desde a elaboração dos experimentos que possam testar empiricamente as representações mentais que governam como se iniciam as intenções pragmáticas ${ }^{1}$ de produzir um texto (POPPER, 2004, p. 41-43), como são gerados os significados a serem lexicalizados, enfim, todas as etapas de processamento até a execução que exterioriza o texto, monitorado continuamente pelo locutor e acessível à inspeção experimental.

Produzir um texto oral é muito mais complexo do que entendê-lo. Conforme abaixo,

Isso ocorre porque o planejamento de uma sentença demanda inerentemente inúmeros recursos; num espaço de tempo muito curto, os falantes devem resolver a competição entre representações simultaneamente ativadas a fim de posicionar de forma correta inúmeros itens da mesma categoria lexical dentro de um mesmo marco hierarquicamente ordenado (BREHM; GOLDRICK, 2016, p. 504 [as traduções para o português foram efetuadas pela autora] ${ }^{2}$ ).

Começa pelo fato de que o falante é responsável pela produção do texto: é ele quem decide sobre o que vai falar e como, de acordo com suas intenções pragmáticas, enquanto o ouvinte deverá estar atento para reconhecer, compreender e interpretar as mensagens que escuta.

Os gestos motores silábicos do aparelho fonador, automatizados no processo de aquisição da linguagem, são a etapa final da produção oral (acompanhados pela monitoria), que se inicia, como mencionei, com a intenção pragmática da fala e com a mensagem, ou seja, o tema ou resumo do que se vai falar.

Teorias opostas explicam o formato dos léxicos mentais ${ }^{3} \mathrm{e}$ a respectiva busca lexical, dando origem, portanto, a modelos experimentais divergentes. Os modelos psicolinguísticos de produção da linguagem verbal oral têm que dar conta de como somos capazes de produzir palavras numa velocidade de até três por segundo, isto é, 180 por minuto. 


\section{Precursores}

Os primeiros modelos que fizeram uma distinção entre produção e compreensão da linguagem verbal provêm da neurologia. O pioneiro foi Paul Broca (2004): em 1861, examinou post mortem o cérebro de um paciente que tinha perdido a capacidade de produzir qualquer palavra, salvo o monossílabo tan, mas entendia o que lhe diziam. Ao examinar o cérebro, Broca verificou que a lesão estava localizada na terceira circunvolução frontal do hemisfério esquerdo, antes do córtex motor e acima da fissura transversal, conhecida como fissura de Sylvius, que separa a região temporal da parietal e de parte da região frontal. A área de Broca é formada por duas partes, denominadas áreas de Brodmann 45 e 44, conforme o mapeamento publicado em 1909 por esse cientista, baseado na organização citoarquitetônica dos neurônios ${ }^{4}$ Lesões nessa área provocavam o que ficou conhecido como afasia de Broca ou de produção.

Após os achados de Broca (2004), Wernicke (CAMPOS FILHO, 2002-2003), em 1874, formulou a hipótese de uma conexão entre a parte posterior do giro temporal do hemisfério esquerdo, que processa as imagens sensoriais acústicas das palavras com a que processa as imagens motoras de palavras e sílabas: isto explicaria por que pacientes com lesões na depois denominada área 22 de Brodmann (vide Figura 1), localizada na parte posterior do giro temporal (GTS), do hemisfério esquerdo, tivessem a compreensão verbal comprometida, embora eles produzissem um discurso fluente, mas sem sentido, conhecido como discurso da jargonofasia. A denominação corrente para esse tipo de afasia passou a ser afasia de recepção ou receptiva.

\section{Modelos psicolinguísticos de produção da linguagem verbal}

No que diz respeito, em particular, à produção da linguagem, o alvo da psicolinguística é explicar como falantes reais, em tempo real, recuperam os elementos de linguagem de sua memória permanente e os combinam a fim de comunicar suas ideias (BOCK; HUITEMA, 1999, p. 3655).

speakers in real time retrieve and assemble elements of language from long-term memory in order to communicate their ideas.

Os modelos desenvolvidos pela neurolinguística que ampliaram e/ou refutaram os marcos iniciais plantados por 
Broca e Wernicke alimentaram as abordagens seguidas pela psicolinguística. Esta ciência examina a compreensão e a produção da linguagem verbal como processo, bem como apresenta modelos explicativos sobre a aquisição das línguas e a aprendizagem dos sistemas escritos. $\mathrm{O}$ foco, portanto, não é a descrição da estrutura do Sistema Nervoso Central, mas testar hipóteses e teorias que expliquem como ele funciona quando recebemos e produzimos mensagens verbais, bem como o modo de adquirirmos e aprendermos tais capacidades.

Figura 1. Novas partições do SNC para as funções da linguagem verbal oral. Vide a área de Broca, localizada no giro frontal inferior (GFI) e a área de Wernicke, localizada no giro temporal superior (GTS), ambas no hemisfério esquerdo.

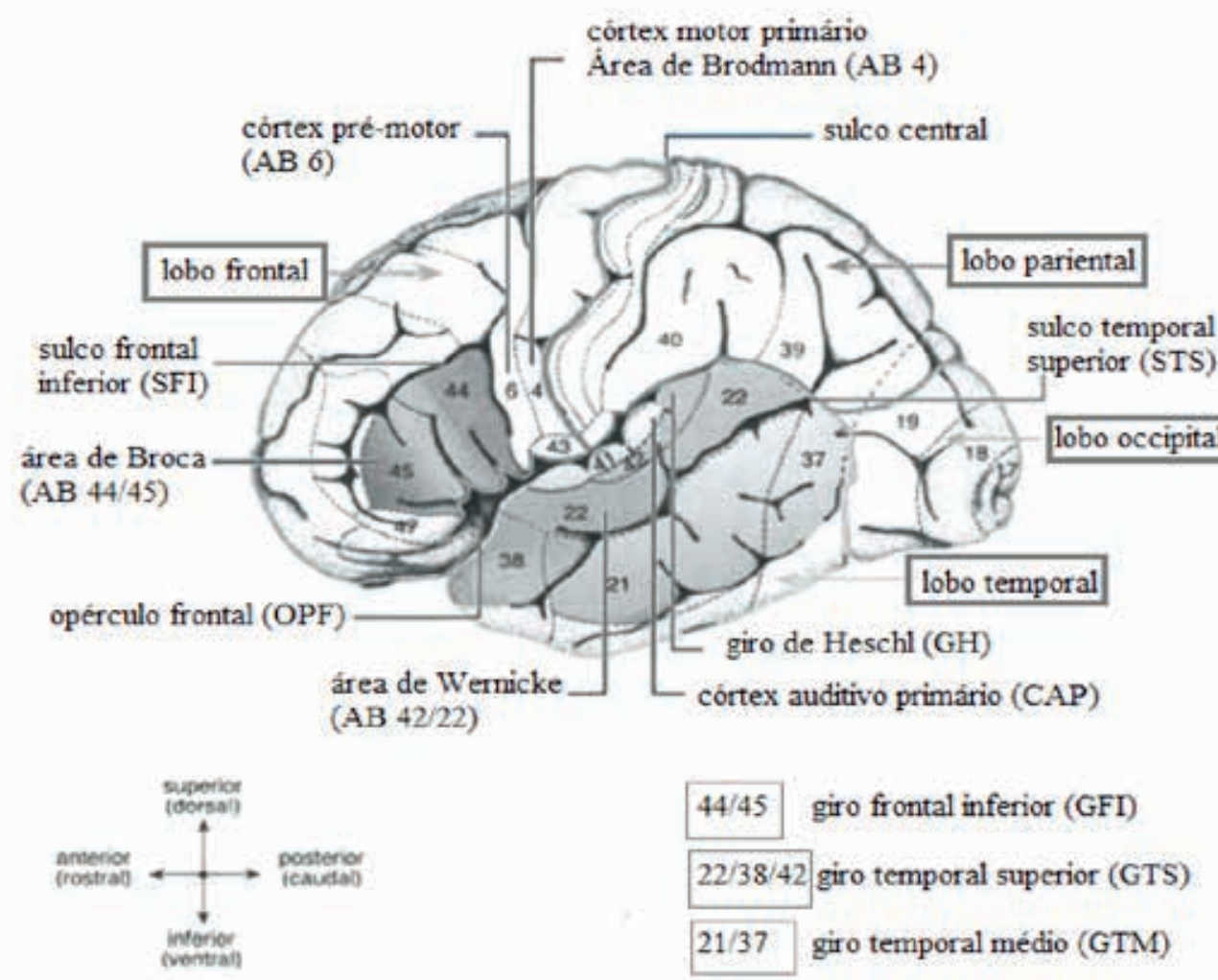

Fonte: Friederici (2011, adaptado). 
Conforme se verá, a metodologia da pesquisa é bastante diversa e, por muito tempo, baseou-se, principalmente, nos dados empíricos fornecidos pelos Fenômenos dos Deslizes da Língua (FDL), no original em inglês, Slip of the Tongue Phenomena (STP), (BROWN; McNEILL, 1966). Tais erros são produzidos quando falamos: tanto podem ser em nível do traço fonético, como no exemplo "poneca de bano" ao invés de "boneca de pano", quanto noutros níveis, como o do fonema: "bosa rela" por "rosa bela"; nível silábico: "tisa de cajolos" por "casa de tijolos"; nível morfológico: "acidoso dolorente" por "acidente doloroso"; nível lexical: "dolorente acidoso" por acidente doloroso"; nível sintático: "Ele dormiu por causa que estava com sono" por "Ele dormiu porque estava com sono"; nível semântico: "O médico prestou assistência técnica ao paciente".

O design experimental foi incrementado com o uso de novas tecnologias como, por exemplo, a técnica de potenciais evocados (PE), que são respostas elétricas do Sistema Nervoso Central ou Periférico a estímulos auditivos, visuais ou tácteis, recebidos pelos respectivos sensores.

\section{Modelos de produção verbal oral}

Cabe destacar que, epistemologicamente ${ }^{6}$, os modelos de produção oral se distinguem entre si em como explicam o modo e a origem do processamento. Um grupo, e nele se inclui o primeiro modelo psicolinguístico de produção, formulado por Victoria Fromkin (1973), considera que o processamento ocorre em cada nível linguístico de modo independente, ou seja, encapsulado, de acordo com a proposta posterior de Fodor (1983), sobre a modularidade da mente, embora a teoria

${ }^{6}$ Epistem ologia: ramo da filosofia que estuda a origem do conhecimento, como, se dos sentidos em direção à cognição ou o inverso, ou em ambas as direções de modo interativo; se o conhecimento é inato, necessitando apenas ser testado pela experiência, ou se é aprendido, ou se, novamente, as duas formas de conhecer coexistem. de Fodor seja sobre percepção. O processamento passa para o nível seguinte de forma serial, ou seja, cada erro só ocorre em cada nível e não afeta os demais. Quanto à origem, esse grupo propõe que o processamento se inicia no nível semântico. Para os conexionistas, o processamento ocorre em paralelo, através de redes, formadas por inúmeros nós interconectados entre si.

\section{A proposta de Fromkin}

Por ter sido o primeiro modelo psicolinguístico de produção oral, exporei brevemente a proposta de Fromkin. Essa 
pesquisadora se baseou na coleta de milhares de Fenômenos dos Deslizes da Língua (FDL, STP) na UCLA, Universidade da Califórnia em Los Ângeles, da qual foi Reitora, e foi a análise desses dados que deu suporte empírico à proposta, de acordo com a seguinte ordem serial:

1. geração do significado intencionado (Nível Semântico);

2. formulação das estruturas sintáticas (Nível Sintático);

3. determinação do contorno entonacional e do posicionamento do acento primário (Nível Fonológico Suprassegmental);

4. seleção das palavras (Nível Lexical);

4.1 radicais referentes à significação externa (substantivos, verbos e adjetivos), inseridos no marco sintático;

4.2 adição de morfemas gramaticais livres ou presos;

5. adição das representações fonêmicas e aplicação das regras fonológicas.

Seguem esclarecimentos adicionais sobre conceitos utilizados no modelo.

Contorno entonacional: é o padrão de entoação que modula as diferenças, por exemplo, entre afirmação, ordem, pergunta, negação, etc.

Acento primário: é aquele que assinala a sílaba mais saliente no vocábulo, mais especificamente, o centro da sílaba. No português brasileiro, doravante $\mathrm{PB}$, é a vogal mais intensa (acento de intensidade) em relação às demais. Noutras línguas, é a duração maior, como no latim e, noutras ainda, é o tom, como no chinês.

Nível Fonológico Suprassegmental: suprassegmento é uma metáfora espacial que se refere ao que está sobre o segmento, ou seja, o fonema. $\mathrm{O}$ suprassegmento abrange o que já expliquei: a intensidade, a duração, o tom e a entoação.

Nível Lexical: refere-se, no caso da produção oral, à recuperação das unidades dotadas de significado para revestir os conceitos, que vão sendo arquivadas no léxico mental à medida que o indivíduo incorpora novos itens. No modelo de Fromkin se infere que os itens (ou morfemas) acerca dos conceitos puramente gramaticais são em número fechado e limitado e estão num arquivo separado daquele que arrola os radicais dos verbos, substantivos e adjetivos (o que foi comprovado pelos experimentos da neurociência (FRIEDERICI, 2011). 
A ordem de processamento e a modularidade de cada nível são rigorosas. Isso implica, por exemplo, que a estrutura sintática seja acionada antes da inserção dos radicais dos substantivos, verbos e adjetivos e estes antes dos morfemas gramaticais livres e presos.

Morfemas gramaticais livres ou presos: os morfemas gamaticais presos são aqueles que só existem aderidos a um radical ou a outro morfema gramatical livre, como é exemplo o morfema de plural, nos substantivos, adjetivos ou pronomes e artigos do PB. Os morfemas gamaticais livres não vêm aderidos a um radical: na escrita, caracterizam- se pelos espaços em branco que os delimitam, como a preposição "de", por exemplo.

Adição das representações fonêmicas e aplicação das regras fonológicas: as representações mentais das unidades referidas se combinam para formar as palavras, e as combinações acarretam mudanças determinadas pelo que Fromkin denomina de regras fonológicas. Exemplifico com o PB. Quando você adiciona o sufixo de primeira pessoa do singular $/ \mathrm{u} /$ ao tema do presente do indicativo (que, nas três pessoas do singular e na terceira do plural recebe o acento de intensidade maior na última vogal do radical), aplica-se a regra de assimilação da vogal temática pelo /u/, como em "pago" $\rightarrow$ /'paga/ + /u/= /'pagu/.

\section{A proposta de Garret}

Antes de eu passar à exposição do modelo de produção serial da linguagem verbal oral mais conhecido, proposto por Levelt e colegas (1999), menciono brevemente outra proposta influente dos pioneiros dos modelos seriais, a de Garrett (1980). O primeiro nível, no qual é gerado o significado, ele o denomina de Nível da Mensagem, rótulo que será preservado por Levelt e colegas. É preciso ter cautela e não confundir "Mensagem/'

7 WAGNER, 2015 , p.54: Utterances are planned and realized incrementally. Which information is salient or attended to prior to initiating an utterance has influences on choices in argument structure and word order, and affects the prosodic prominence of the constituents involved. com esse mesmo termo quando é usado como tradução de utterance, ou quando integra o modelo das funções da linguagem de R. Jakobson. O Nível da Mensagem, nos modelos de produção verbal, significa o nível mais alto e abstrato quando são resumidos os conceitos que deverão posteriormente ser lexicalizados e inseridos nas estruturas sintáticas.

Esclareço que Levelt e colegas tratam do início da produção verbal postulam que as "mensagens são planejadas e realizadas de forma incremental. Quais informações são 
salientes ou contempladas antes de se iniciar uma mensagem influenciam as escolhas na estruturação dos argumentos e na ordem das palavras e a proeminência prosódica dos constituintes envolvidos" (WAGNER, 2015, p.5417). A explicação de Wagner se aplica ao diálogo em curso, na sequência à fala de um interlocutor, e não à abertura de um tópico, a qual começa por uma decisão pragmática ditada por fatores determinantes, tais como o motivo, o(s) destinatário(s), o tópico, o gênero, a situação comunicativa e assim por diante, pois desta decisão decorre o estilo ou registro a ser empregado no texto.

O início das pesquisas sobre produção da fala se beneficiou dos trabalhos de Goldman-Eisler (1958) sobre pausa e hesitação. Ela demonstrou que são precisamente os dois processos, o planejamento e a escolha das palavras não gramaticais, caracterizados pela criatividade das atividades cognitivas mais altas, que requerem as pausas e hesitações. As primeiras pesquisas sistemáticas sobre as pausas e hesitações no português brasileiro foram conduzidas por Scliar-Cabral (1981).

Ao contrário de Fromkin, Garrett não menciona a seleção do padrão entonacional. Segue-se o Nível da Sentença, subdividido em Nível Funcional e Nível Posicional. No Nível Funcional ocorre a lexicalização, isto é, a recuperação dos itens lexicais, a respectiva ordem e demais regras gramaticais, de que resulta a cadeia das unidades, pronta para ser articulada no nível motor, que ele denomina de posicional.

\section{Levelt e colegas}

Passo, então, a explicar o modelo de Levelt e colegas. Em um artigo clássico (LEVELT; ROELOFS; MEYER, 1999, p. 1), eles explicam que as primeiras palavras produzidas pela criança (isso ocorre, em geral, por volta de um ano de idade) são precedidas e garantidas pelo fato de que ela, por um lado, já internalizou noções de agentividade, interatividade, estruturas causais e temporais dos eventos e de permanência e localização de objetos, noções agarradas por rótulos lexicais, que a criança escutou, ditos pelos adultos nos mesmos contextos de uso; por outro lado, ela registrou um repertório de gestos articulatórios sílábicos, no período do balbucio, ainda sem significado. Na fase que antecede a produção das primeiras palavras, os dois sistemas, o sistema conceitual e o motor articulatório são independentes. 
Essa introdução ao modelo de produção verbal oral de Levelt e colegas assinala algumas propriedades importantes que vou comentar:

$1^{a}$ - Precedência do input sobre o output e dependência deste último àquele, ou seja, para falar, a criança terá que ter ouvido os adultos falarem e dará demonstrações de ter entendido algo do que lhe disserem, embora não possa, ainda, produzir os mesmos enunciados que entendeu (evidentemente, no caso da criança surda, ela terá que ver os gestos que os adultos lhe fazem e entendê-los, antes de poder produzir as primeiras palavras em L.I.B.R.A.S.).

$2^{\mathrm{a}}$ - Produzir uma mensagem verbal implica traduzir conceitos, noções, pensamentos lexicáveis em palavras (é uma das etapas iniciais na produção verbal).

$3^{a}$ - A etapa final na produção verbal oral é a execução dos gestos motores automatizados do aparelho fonador: ela ocorre a partir da ativação das sílabas fonéticas que formam a palavra escolhida, constantes no silabário que começa a ser fixado na fase do balbucio, de forma independente (protossilabário). O silabário propriamente dito surge quando as sílabas entram na composição de palavras, ou seja, de unidades com significado. Então, o silabário vai se ampliando e refinando, numa complexidade crescente, à medida que a criança se desenvolve. Eu postulo que, assim como acontece com o declínio da percepção categorial fonética inata no primeiro ano de vida (SCLIAR-CABRAL, 2004), em que a criança perde a sensibilidade para certos traços fonéticos, realinha categorias e estreita ou amplia seu âmbito (JUSCZYK, 1997, p. 73/74), na consolidação do silabário, ocorre uma inibição ao registro de esquemas silábicos que contrariam as combinatórias e/ou posições possíveis na variedade sociolinguística que a criança está adquirindo, o que bloqueia o seu registro no córtex prémotor (vide Fig. 1, que corresponde à área 6 de Brodman). A limitação é necessária para a automatização dos padrões, o que possibilitará o acionamento sinérgico e eficiente de todos os músculos envolvidos nos gestos articulatórios silábicos dos vocábulos.

A articulação das sílabas está entre os padrões motores mais exercitados (LEVELT, 2000, p. 13.469). Assim, apesar da complexidade dos comandos que devem acionar, sinergicamente, músculos pertencentes a diferentes sistemas 
do aparelho fonador, a criança, por volta dos doze meses, já demonstra domínio articulatório de algumas sílabas como / $\mathrm{pa} /$, /ma/, /da/, /ne/ e logo terá um repertório de cinquenta palavras. A seguir, os níveis propostos por Levelt e colegas.

\section{Nível da mensagem}

O Nível da Mensagem é o primeiro proposto por Levelt e colegas: é o mais alto e abstrato e deslancha os conceitos que deverão posteriormente ser lexicalizados e inseridos nas estruturas sintáticas. É movido pelas intenções pragmáticas dos falantes, tanto ao iniciarem a conversação, quanto quando a mantêm.

\section{Preparação conceitual}

Para Levelt e colegas (1999), depois de definida a mensagem, segue-se a preparação conceitual, na forma de conceitos lexicais, que eles formalizam usando letras maiúsculas. Levelt (2000, p. 13, 464) propõe a noção de perspectiva: "[...] um primeiro passo na preparação do conceito de uma palavra é focalizar em um conceito cuja expressão servirá a um alvo comunicativo específico." Os conceitos lexicais podem ser competitivos, pois várias possibilidades competem entre si, o que acarreta a indeterminação do que será selecionado: é fonte de dificuldades nos testes de produção da fala. Um exemplo dado por Levelt (2000), adaptado ao PB, é o de, apresentada a figura de um cavalo, o sujeito poder acionar os seguintes conceitos lexicais: CAVALO, BICHO, ANIMAL, JUMENTO, JEGUE, PINGO, POTRO, entre outros. Os conceitos lexicais integram o que tradicionalmente é conhecido em psicolinguística como memória semântica.

\section{Seleção lexical}

Levelt e colegas (1999) propõem representações intermediárias abstratas que denominam de lemas, os quais contêm todas as propriedades gramaticais da referida categoria lexical. Por exemplo, depois de selecionado, o lemalav, do conceito LAVAVAS, ocupa um nó, que assinala que se trata de 
um verbo com dois argumentos (agente e objeto), com diacríticos que marcam pessoa/número ( $2^{\mathrm{a}}$ /singular); tempo/aspecto/ modo (pretérito/imperfeito/indicativo) e conjugação $\left(1^{\mathrm{a}}\right)$.

\section{Codificação morfofonológica e silabificação}

A ativação se espalha para o terceiro nível chamado pelos autores de forma, a qual contém os nós de um ou mais morfemas integrantes da palavra e os nós dos respectivos fonemas que os constituem, inclusive com a posição ocupada por cada um, a saber: $|\operatorname{lav}|,|\mathrm{a}|$, $|\mathrm{va}|,|\mathrm{s}|$; /1/, /a/, /v/, /a/, /v/, $/ \mathrm{a} /,|S|$. Uma vez ativado o nó que contém um dado morfema, estão determinados quais os seus fonemas e em que ordem estão. Da combinação dos morfemas resulta o output seguinte, que é a palavra fonológica.

\section{Codificação fonética}

À codificação fonética cabe computar a pontuação gestual da palavra fonológica, ou seja, especificar a tarefa articulatória na produção da palavra, conforme a teoria de Browman e Goldstein (1988), com duas consequências importantes: a especificação das sílabas fonéticas que serão ativadas no silabário fonético para que o programa motor acione os músculos adequados para a produção dos gestos fonatórios e a atribuição da prosódia, ou seja, como se distribuem os acentos. No exemplo dado, as três primeiras sílabas fonéticas são [la], [va], [ve ${ }^{*}$ ( ${ }^{*}$ pode ter diversas realizações fonéticas).

A ativação das sílabas no silabário dependerá das mudanças fonéticas decorrentes do encontro (junturas ou sândi interno) entre morfemas presos dentro de palavras ou entre palavras (junturas ou sândi externo). Veja o exemplo de um encontro interno que provoca mudança silábica: IN + EXATO $\rightarrow$ [i.ne.'za.tu] e, agora, um exemplo de encontro externo: MAR + AGITADO $\rightarrow$ ['ma.ra.3i.'ta.du].

\section{Articulação}

Os gestos da sílaba fonética são executados pelo aparelho fonador através do controle de um sistema neural 
computacional de gestos altamente complexos deste sistema motor, no qual são necessárias sinergias que coordenem não só vários músculos em movimentos simultâneos para a obtenção de um mesmo alvo, quanto, simultaneamente, a antecipação dos gestos da sílaba seguinte, com todos os efeitos das mudanças contextuais decorrentes, já que a execução é dinâmica. As pesquisas pioneiras de Albano (2001, 2012, 2016) dão suporte empírico a tais enfoques teóricos sobre o processamento da fala, com dados do PB e respectiva explanação.

\section{Autorregulação}

Não só é possível constatar falhas na fala de nosso interlocutor, quanto em nossa própria fala, pois, quando falamos, o sinal acústico retorna em ondas aos nossos ouvidos. Além disto, podemos autorregular nosso próprio discurso interior: isto está demonstrado porque afeta o tempo de reação da fala já que a codificação se torna mais lenta. Levelt (1989) propõe que a fala interior tenha uma representação fonética, portanto, depois da codificação fonética. $\mathrm{O}$ autor, contudo, não menciona o papel que a memória de trabalho, principalmente o repetidor fonológico (phonologic loop, Baddeley, 1986), desempenharia para processar tais informações.

Chamo a atenção do leitor para dois fatos importantes. $\mathrm{O}$ primeiro é o de que um modelo psicolinguístico de produção oral procura dar conta dos processos nela envolvidos, portanto ele explica o conhecimento para o uso que o falante tem de uma dada variedade sociolinguística. Não significa que esse falante, conscientemente, saiba definir as noções de agentividade ou de objeto, em $L A V A V A S$, embora tenha o conhecimento para o uso de que esse verbo exija alguém que pratique a ação de lavar e de que essa ação não se complete no próprio verbo, mas também exija algo a ser lavado.

O segundo fato é o de que as notações e rótulos empregados pelo cientista não estão representados na mente do falante: eles procuram dar conta, novamente, dos processos, da forma mais econômica, exaustiva e coerente: o código mental das transformações fisioquímicas em cada um dos estratos ainda não foi decifrado.

Veja a adaptação ao português de Levelt e colegas (1999, p. 4) de uma rede lexical subjacente ao acesso lexical de LAVAVAS. 
Figura 2. Fragmento de uma rede lexical, adaptada ao português, subjacente ao acesso lexical da palavra LAVAVAS. Conforme a proposta de Levelt e colegas, o espraiamento da ativação da rede passa por três estratos. Os nós, bem ao alto, representam os conceitos lexicais; os nós no estrato dos lemas representam a classe sintática da palavra ou o lema e suas respectivas propriedades; os nós do estrato da forma representam os morfemas com seus fonemas constituintes: incluem-se nesse estrato os nós das sílabas (On é a abreviatura de onset, a(s) consoante(s) que inicia(m) a sílaba, ou seja, o ataque ou aclive; $\mathrm{Nu}$ é a abreviatura de núcleo ou centro silábico e $\mathrm{Co}$ a abreviatura de coda, ou margem consonantal, ou declive da sílaba).

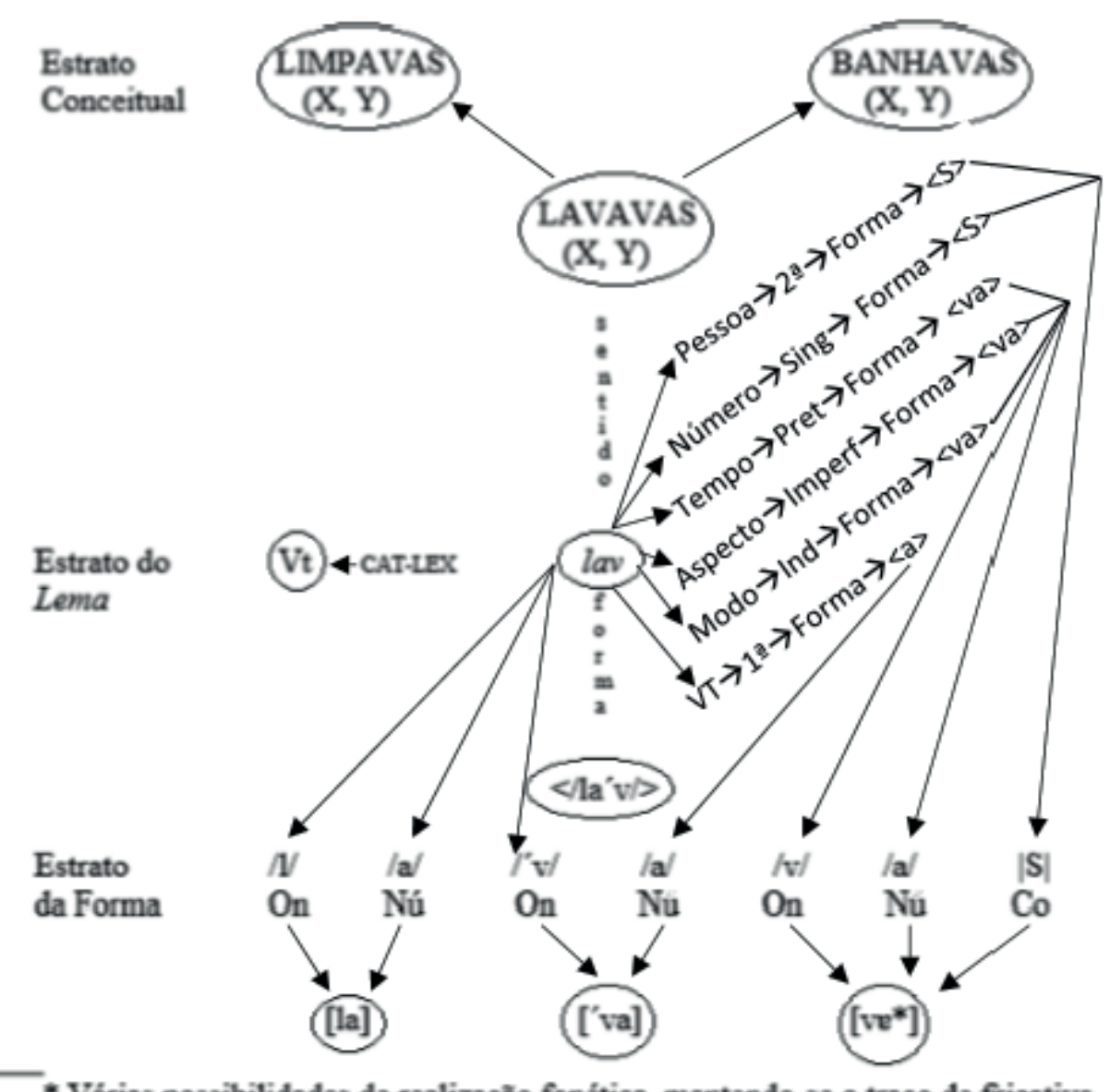

Fonte: Elaboração da autora - figura baseada no esquema apresentado em Levelt, Roelofs e Meyer (1999, p. 4). 


\section{Modelos de processamento em paralelo}

Os modelos de processamento em paralelo da produção oral são diferentes dos seriais, porque admitem a ativação simultânea e recursiva do que está sendo processado.

O que isto significa? Significa que não só várias unidades (conceitos, morfemas, sílabas, fonemas e traços fonéticos) em cada nível da rede que partilham traços em comum são ativadas simultaneamente, competindo entre si, quanto os diferentes níveis (semântico, lexical e fonológico) são ativados também simultaneamente, interagindo entre si: o resultado dessa interação retorna ao nó de origem, havendo uma retroalimentação (DELL, 1986). Esses modelos são também chamados de conexionistas. Por exemplo, o nó do fonema /b/ pode estar conectado a todos os nós onde tal fonema consta, como em /'bala/, /'bolU/, /su'bi/ etc. Do ponto de vista semântico, o nó de BOLO está conectado a DOCE, ALIMENTO, FARINHA, AÇÚCAR, FERMENTO, ANIVERSÁRIO etc.

\section{Uma teoria integrada da produção e compreensão da linguagem}

Pickering e Garrod (2013) propuseram uma teoria integrada da produção e compreensão da linguagem, que sintetizarei para o leitor. Segundo essa proposta (PICKERING; GARROD, 2013, p. 1), ambas estão entrelaçadas de tal modo que não só o falante prediz o que ele próprio vai falar, mas também o que seu interlocutor vai dizer: produção e compreensão são, respectivamente, formas de agir e de perceber a ação. Os autores asseveram que existe evidência do entrelaçamento entre produção e compreensão na ação, na percepção da ação e na ação conjunta. Tal evidência é explicada por eles pela predição: os autores assumem que os agentes constroem modelos antecipados de suas ações antes de executá-las, e aqueles que percebem tais ações imitam-nas internamente, construindo, então, modelos antecipados de ação. Tanto para a produção quanto para a compreensão, os autores aceitam a passagem respectiva pelos níveis semântico $\rightarrow$ sintático $\rightarrow$ fonológico/ fonológico $\rightarrow$ sintático $\rightarrow$ semântico.

Embora a teoria de Pickering e Garrod (2013) apresente alguns pontos empiricamente comprovados, como a existência das conexões entre as áreas de processamento receptivo e 
de produção da linguagem verbal oral e a necessidade das representações perceptivas para monitorar a produção, ela não dá conta de muitas especificidades envolvidas em cada um dos processamentos, a começar pela fisiologia do aparelho auditivo e do aparelho fonador e sua contraparte no sistema nervoso central que envolve, prioritariamente, no primeiro caso, processos aferentes (de origem sensorial) e, no segundo caso, processos eferentes (com finalização motora), dependentes dos primeiros Os processos perceptivos operam com o reconhecimento da frase ouvida e não por imitação, reproduzindo fielmente a fala ouvida e até antecipando o que o interlocutor falará, como postulam os autores: isto seria impossível, por várias razões, entre elas, pelo fato de que não há duas pessoas que falem (ou que possam falar) do mesmo jeito e, também, pela razão primordial da comunicação linguística: trocamos ideias para ouvir informação nova e não o óbvio ululante.

\section{Modelos recentes com base na neurociência: conceptualização}

2011 p. 527: Recent $\mathrm{n}$ e u r o i m a g i $\mathrm{g}$ studies demonstrate two striking results: the participation of mod ality specific sensory, motor, and emotion systems in language comprehension, and the existence of large brain regions that participate in comprehension tasks but are not modalityspecific. These latter regions, which include the inferior parietal lobe and much of the temporal lobe, lie at convergences of multiple perceptual processing streams. These convergences enable increasingly abstract, supramodal representations of perceptual experience that support a variety of conceptual functions including object recognition, social cognition, language, and the remarkable human capacity to remember the past and imagine the future.

\begin{abstract}
recentes modelos com base na neuro-imagem demonstram dois resultados surpreendentes: a participação de sistemas específicos às modalidades sensoriais, motoras e emocionais para a compreensão da linguagem e a existência de vastas regiões cerebrais que participam de tarefas de compreensão, mas não específicas a cada modalidade. Essas últimas regiões, que incluem o lobo parietal inferior e grande parte do lobo temporal, se encontram na convergência de múltiplas cadeias de processamento perceptual de. Essas convergências permitem representações supramodais cumulativamente mais abstratas da experiência perceptual que garantem uma variedade de funções conceituais, inclusive o reconhecimento de objetos, a cognição social, a linguagem e a notável capacidade humana de lembrar o passado e de imaginar o futuro. (BINDER; DESAI, 2011 p. 5278)
\end{abstract}

Tais modelos sustentam que a largada para a produção de uma mensagem verbal oral tem origem na convergência de informações provindas de várias áreas e conduzidas 
${ }^{9}$ WILSON; FOGLIA, 2015, PS. 30-31: (1a) After wading barefoot in the lake, Erik used his shirt to dry his feet. (b) After wading barefoot in the lake, Erik used his glasses to dry his feet. Although both (1a) and (1b) are grammatical, the reason why $(1 b)$ does not make the same kind of sense as (1a) does is because the affordances of glasses do not mesh with the action of drying. Understanding the meaning of such sentences requires $\mathrm{know}$ in $\mathrm{g}$ th e possibilities offered by objects referred to in them. These possibilities are constrained by the interaction between bodily capabilities and the referents.

${ }^{10}$ A memória declarativa ("saber o quêe"), também conhecida como memória explícita, é a memória dos fatos e eventos e se refere às memórias que podem ser lembradas de modo consciente. Subdivides e em memória episódica e semântica. Há consenso de que a s experiências multissensoriais deixam o registro dos resultados do processamento da informação, distribuído em cada uma das áreas secundárias em que ocorreram pela primeira vez tais processamentos: por exemplo, ao tocar violão, lendo a partitura, as percepções são simultaneamente visuais, auditivas e somestésicas - os respectivos neurônios que as codificaram pela primeira vez, as registram em memórias específicas, as quais são simultaneamente evocadas, ao relembrar a experiência. Vários estudos demonstram que a autorregulação sensorial, como a auditiva e a somestésica desempenham um papel crítico durante por vários circuitos (pathways ou fascículos), entre as quais se incluem tanto aquelas processadas em giros neurais em modalidades perceptuais bem específicas, como, por exemplo, a parte posterior do giro fusiforme do hemisfério direito, que reconhece um rosto, quanto conceitos imaginários ou de natureza totalmente abstrata, sem contrapartida referencial concreta, como, por exemplo, todos os conceitos envolvidos nas palavras que acabo de escrever, desde "quanto" até "concreta". Evidentemente, o exemplo que acabo de oferecer ao leitor, de modo fortuito, nada tem a ver com os exemplos propositais, oferecidos pelos defensores da teoria Embodied cognition (Cognição corporificada): "Depois de vadear descalço pelo lago, Érico usou a camisa para secar os pés", em contraste com "Depois de vadear descalço pelo lago, Érico usou os óculos para secar os pés", sob a alegação de que compreender a diferença entre ambos repousa no fato de que "a finalidade dos óculos não emparelha com a ação de secar. Entender o sentido de tais frases exige conhecer as possibilidades oferecidas pelos objetos a que se referem. Essas possibilidades são limitadas pela interação entre as capacidades corporais e os referentes" (WILSON; FOGLIA, 2015, PS. 30-319). Se a produção de enunciados se restringisse a tais exemplos, nos quais, para compreendê-los, bastaria verificar a compatibilidade entre capacidades de ação corporal e os objetos circundantes que os motivam, convenhamos, em nível explicativo, ela pouco distaria do paradigma estímulo/resposta. Contudo, não se confirma, no momento inicial da produção verbal, que toda a elaboração da mensagem, ou seja, da conceituação lexical, seja modular e serial.

É necessário, ainda, quando se examinam as bases neurais da conceptualização, verificar a distinção aceita por muitos pesquisadores entre memória declarativa e procedimenta ${ }^{10}$.

Em decorrência, tanto Levelt e colegas (1999), quanto Roelofs (2014) assinalam o papel da memória declarativa na etapa da conceptualização e da busca lexical, enquanto a memória procedimental intervém nos processos regidos por regras, tais como a sintaxe; as de derivação morfológica; quais os fonemas e sua posição (regras fonotáticas) que integram uma palavra, depois de selecionada, bem como sua prosódia; as regras de juntura fechada tanto entre palavras quanto entre morfemas dentro da palavra (sândi); os padrões de entoação 
a produção da fala (BEHROOZMAND et al., 2015, p. 418). A $m$ e $m$ ó $r$ i procedimental ("saber como"), ta m bém conhecida como memória implícita, é o conhecimento para o uso, é a memória inconsciente das habilidades, particularmente o uso de objetos ou gestos do corpo, como caminhar, produzir os sons da fala ou andar de bicicleta. e todas as variantes fonéticas condicionadas pela variedade sociolinguística adquirida pelo falante. A neurociência cognitiva fornece evidências robustas sobre a existência no cérebro de sistemas distintos para a memória declarativa e procedimental (consulte-se o livro de EICHENBAUM, 2012). Mais recentemente, Roelofs e Ferreira (2017) confirmam que existe considerável evidência neurocientífica em favor de sistemas cerebrais distintos para as memórias declarativa e procedimental.

\section{Comentários finais}

Procurei expor a trajetória percorrida desde os precursores até as propostas mais recentes sobre os modelos de produção da linguagem verbal oral: não são poucos os desafios metodológicos para a construção do design experimental para testar empiricamente as hipóteses de trabalho, em particular, sobre as fases iniciais, quando o falante formula suas intenções pragmáticas e toma as decisões sobre o que quer dizer e como para atingir seus alvos. Desde a primeira proposta de Fromkin até os dias atuais, tem havido um consenso de que no primeiro momento de formulação da intencionalidade, convergem múltiplas informações provindas de várias áreas, através de pathways, em especial, aquelas originárias do córtex associativo temporal e parietal inferior. Tudo indica que, à medida que os níveis de processamento se tornam mais baixos, com paradigmas fechados, constituídos por um menor número de elementos, os processamentos são automatizados e encapsulados. Tal enfoque vai ao encontro da proposta de Fodor (1983), ao dividir os processamentos mentais em horizontais (os chamados processamentos criativos) e verticais (os processamentos compulsórios e modulares).

\section{REFERÊNCIAS}

ALBANO, E. C. O gesto e suas Bordas: Esboço de Fonologia Acústico-Articulatória do Português Brasileiro. Campinas: Mercado de Letras, 2001.

. Uma introdução à dinâmica em fonologia, com foco nos trabalhos desta coletânea. Revista da ABRALIN, v. 2, p. 1-30, 2012. 
ALBANO, E. C. Conditions favoring biomechanically driven CV co-occurrence in lexicons. Journal of Phonetics, v. 55, p. 78-95, 2016.

BADDELEY, A. D. Working memory. Oxford, U.K.: Clarendon, 1986.

BEHROOZMAND, R.; SHEBEK, R.; HANSEN, D. R.; OYA, H.; ROBIN, D. A.; HOWARD, III, M. A.; GREENLEE, J. D.W. Sensory-Motor Networks Involved in Speech Production and Motor Control: An fMRI Study. NeuroImage. v. 109, 1, p. 418-428. Apr. 2015. Disponível em: <https://www.ncbi.nlm.nih.gov/pmc/ articles/ PMC4339397/\#R23>. Acesso em 17/5/2017.

BINDER, J. R.; DESAI, R. H. The neurobiology of semantic memory. Trends Cogn Sci. v. 15, n. 11, p. 527-536, Nov. 2011. Disponível em: $<$ https://www.ncbi.nlm.nih.gov/pmc/articles/PMC3350748/>. Acesso em 17/05/2017.

BOCK, K.; HUITEMA, J. Language production. In: GARROD, S.; PICKERING, M. J. (eds.). Language processing. Hove: Psychology Press, 1999, p. 365-388.

BREHM, L.; GOLDRICK, M. Empirical and conceptual challenges for neurocognitive theories of language production. Cognition and Neuroscience. v. 31, n. 4, p. 504-507, 2016. Disponível em $<\mathrm{http}: / /$ faculty.wcas.northwestern.edu/matt-goldrick/Brehm Goldrick_2015. pdf $>$. Acesso em 30/03/2017.

BROCA, P. Écrits surl'Aphasie (1861-1869). Paris: Harmattan, 2004.

BROWMAN, C. P.; GOLDSTEIN, L. Some notes on syllable structure in articulatory phonology. Phonetica. v. 45, p. $140-$ 55, 1988.

BROWN, R.; McNEILL, D. The "tip of the tongue" phenomenon. Journal of Verbal Learning and Verbal Behavior, v. 5, n. 4, p. 325337, 1966.

CAMPOS FILHO, R. de. Os estudos das afasias por Carl Wernicke. Revista USP, São Paulo, n.56, p. 152-162, dezembro/ fevereiro 2002-2003.

DELL, G. S. A spreading activation theory of retrieval and sentence production. Psychological Review. v. 93, p. 283-321, 1986. 
EICHENBAUM, H. The cognitive neuroscience of memory: an introduction. $2^{\text {nd }}$ ed. Oxford: Oxford University Press, 2012.

FODOR, J. The Modularity of Mind. Cambridge, MA: The MIT, 1983.

FRIEDERICI, A. The current Model. Physiological Reviews. v. 91, n. 4, p. 1357-1392, 2011. Disponível em: <http://www.cbs.mpg.de/ mitarbeiter/friederici/current-model $>$. Acesso em 04/08/2016.

FROMKIN, V. A. Speech Errors as Linguistic Evidence. The Hague, Netherlands: Mouton, 1973.

GARRETT, M. F. The limits of accommodation. In: FROMKIN, V. (ed.). Errors in linguistic performance. New York: Academic, 1980. p. 263-271.

GOLDMAN-EISLER, F. Speech production and the predictability of words in context. Quart. J. Exp. Psychol. v. 10, p. 96-106, 1958.

JUSCZYK, P. W. The Discovery of spoken language. Cambridge, MA: The MIT Press, 1997.

LEVELT, W. J. M. Speaking from intention to articulation. Cambridge, MA: MIT Press, 1989.

Spoken word production: A theory of lexical access. PNAS. v. 98 , n. 23, p. 13464-13471, nov. 6, 2000.

LEVELT, W. J. M.; ROELOFS, A.; MEYER, A. S. A theory of lexical access in speech production. Behavioral and Brain Sciences. v. 22, p. 1-75, 1999.

PICKERING, M. J.; GARROD, S. An integrated theory of language production and comprehension. Behavioral and Brain Sciences. Cambridge, UK: Cambridge University Press, 2013. Disponível em <http://pubman.mpdl.mpg.de/pubman/item/escidoc: 1525227:11/component/escidoc:1786392/Pickering\%20\&\%20 Garrod_BBS_2013_Incl_Commentary.pdf $>$ Acesso em 30/3/2017.

POPPER, K. A lógica da pesquisa científica. São Paulo: Cultrix, 2004.

ROELOFS, A. A dorsal-pathway account of aphasic language production: The WEAVER++/ARC model. Cortex. v. 59, p. 33-48, 2014. 
ROELOFS, A.; FERREIRA, V. S. The Architecture of Speaking. Disponível em $<$ http://www.socsci.ru.nl/ardiroel/Roelofs Ferreira_Chptr_2017.pdf $>$. Acesso em 28/05/2017.

SCLIAR-CABRAL, L. Declínio da percepção categorial fonética inata no primeiro ano de vida. Letras de Hoje. Porto Alegre, v. 39, n. 3, p. 79-87, 2004.

SCLIAR-CABRAL, L.; MARTIM, E. G.; CHIARI, B. M. Fenômenos de pausa e hesitação em língua portuguesa. Anais do $4^{\circ}$ Encontro Nacional de Lingüistas. Rio de Janeiro: PUCRJ, p. 124-141, 1981.

WAGNER, M. Information Structure and Production Planning. In: FÉRY, C.; ISHIHARA, S. (eds.). Oxford Handbook on Information Structure. Oxford: OUP, 2014, p. 541-561. Disponível em < http://www.oxfordhandbooks.com/view/10.1093/oxfordhb /9780199642670.001.0001/oxfordhb-9780199642670-e-39\#p541>. Acesso em 19/4/ 2017.

WILSON, R. A.; FOGLIA, L. Embodied cognition. Stanford encyclopedia, 8/12/2015. Disponível em $<$ https://plato.stanford.edu/ entries/embodied-cognition/>. Acesso em 28/05/2017. 


\section{Abstract \\ Psycholinguistic models of oral verbal language production}

Psycholinguistic models of verbal language production face at the difficulty of formalizing the mental representations that govern pragmatic intentions for producing an oral text, as well as that of the essential concepts, both with the function of guiding textual planning. Such difficulty poses challenges to experimental designs that may falsify working hypotheses (POPPER, 2004, p. 41-43). Most of psycholinguistic models of oral verbal language production refer to the opening of a topic and not to the ongoing dialogue, following the speech of an interlocutor. I refer to precursors from neurology, such as Broca (2004) and Wernicke (CAMPOS FILHO, 2002-2003), and examine the psycholinguistic models, starting with Fromkin's (1973) pioneer one. I dwell more deeply on that of Levelt and colleagues (1999) and mention the more recent contributions (ROELOFS; FERREIRA, 2017).The examples are all adapted to Brazilian Portuguese. I conclude with the hypothesis that, as the processing levels become lower, with closed paradigms, constituted by a smaller number of elements, the processes are automated and encapsulated. This approach is in line with Fodor's (1983) proposal, who divided mental processes into horizontal (the so-called creative) and vertical (compulsory and modular) processes.

Keywords: Psycholinguistic models. Oral Verbal production. Pragmatic Intentions. Message. Planning. 